\title{
Controller entdecken den Vertrieb
}

Das Controlling hat immer mehr Teilbereiche des Unternehmens durchdrungen. Das gilt auch für den Vertrieb. Vertriebscontrolling führt dem WHU-Controllerpanel zufolge mittlerweile die Liste der Spezialisierung des Controllings an, noch vor dem Finanz-Controlling!

Grund dafür ist die erhebliche wirtschaftliche Bedeutung, die dem Vertrieb für die Unternehmen zukommt: Dort werden Absatzmengen und -preise maßgeblich bestimmt. Hinzu kommt, dass im Vertrieb erhebliche Produktivitätsreserven vermutet werden. Manche Vertriebler sehen ihre Tätigkeit noch eher als Kunst denn als Handwerk. Die enge persönliche Beziehung zu den Kunden im Zusammenspiel mit der primär intuitiven Einschätzung von deren Präferenzen und Handlungsweisen führt zu einem Bild, in dem Zahlen keine bestimmende Rolle spielen.

Ein Vertriebscontrolling muss deshalb auf der einen Seite die Finanzperspektive fest im Vertrieb verankern. Vertriebler müssen das Zusammenspiel von Preis- und Mengeneffekten verstehen lernen und „im Schlaf“ beherrschen sowie technische Qualitätsvorteile als Euro-Vorteil ausdrücken können; sie tun sich häufig noch schwer damit, vor professionellen Einkäufern eine Preisprämie zu rechtfertigen.

Ein Vertriebscontrolling hat sich auf der anderen Seite auch mit den Vertriebsprozessen selbst auseinanderzusetzen. Wer Verkaufen als Kunst sieht, fordert für den Prozess hohe Freiheitsgrade. Wer glaubt, dass der reguläre Vertrieb viel mit einer standardisierten Dienstleistung zu tun hat, wird im Sinne einer „Produktionsfunktion für den Vertrieb“ viel mehr strukturierte Vorgaben machen. Im Detail ist zu analysieren, welche der beiden Sichten recht hat bzw. wie weit beide Sichten miteinander zu kombinieren sind.

Wollen Controller dem Vertrieb bei diesen Herausforderungen helfen, müssen auch sie lernen. Ohne ein intimes Verständnis davon, wie der Vertrieb wirklich funktioniert, geht es nicht. Dieses Wissen ist einem „normalen“ Controller nicht

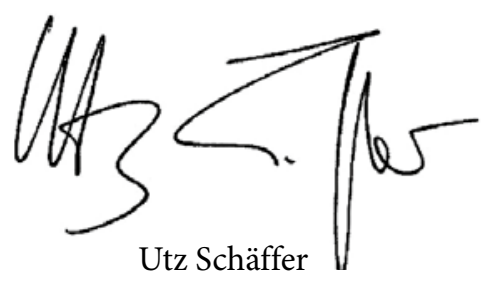

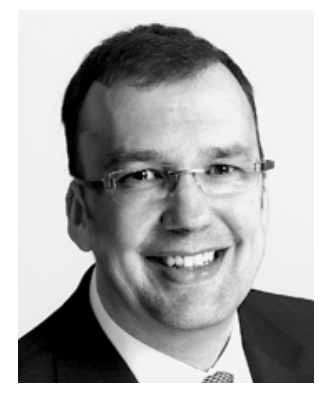

Utz Schäffer

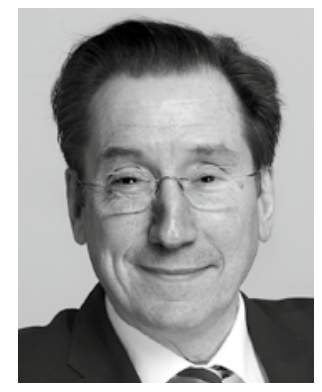

Jürgen Weber

in die Wiege gelegt. In diesem konkreten Geschäftswissen liegt häufig ein Engpass der Wirksamkeit von Controllern auch im Vertrieb. Er ist zugleich der Grund dafür, dass viele Vertriebler Controller lieber gehen als kommen sehen.

Die Lernaufgabe ist aber - wie die Praxis zeigt - nicht unlösbar: So können Controller auch im Vertrieb Karriere machen. Ein besonders exponiertes Beispiel findet sich etwa bei einem international sehr erfolgreichen Großunternehmen im Bereich weißer Ware. Der Vertriebsgeschäftsführer im dreiköpfigen Board war in seiner Karriere zuvor auch Leiter des Zentral-Controllings. Dies sollte Anreiz genug sein, Vertriebscontrolling nicht nur als wichtiges, sondern auch als lohnendes Aufgabenfeld zu sehen!

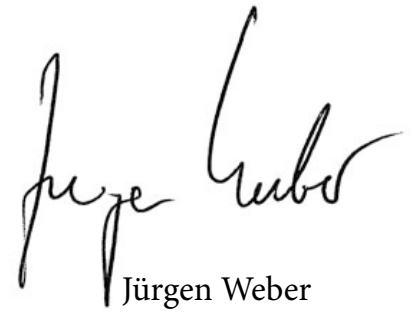

